\title{
Comparison of Surgical Smoke Generated During Electrosurgery with Aerosolized Particulates from Ultrasonic and High-Speed Cutting
}

\author{
Vincent J. Casey (1), ${ }^{1,2}$ Cian Martin, ${ }^{3}$ Peter Curtin, ${ }^{3}$ Kevin Buckley $\mathbb{0},{ }^{3}$ \\ and LaOise M. MCNAMARA ${ }^{1,2}$ \\ ${ }^{1}$ Mechanobiology and Medical Device Research Group (MMDRG), Biomedical Engineering, National University of Ireland \\ Galway, Galway, Ireland; ${ }^{2}$ CÚRAM, SFI Research Centre for Medical Devices, National University of Ireland Galway, \\ Galway, Ireland; and ${ }^{3}$ Stryker, Instruments Innovation Centre, Carrigtwohill, Cork, Ireland
}

(Received 12 March 2020; accepted 31 July 2020; published online 7 August 2020)

Associate Editor Umberto Morbiducci oversaw the review of this article.

\begin{abstract}
Surgical smoke" is an airborne by-product of electrosurgery comprised of vapour and suspended particles. Although concerns exist that exposure may be harmful, there is a poor understanding of the smoke in terms of particle size, morphology, composition and biological viability. Notably, it is not known how the biological tissue source and cutting method influence the smoke. The objective of this study was to develop a collection method for airborne by-product from surgical cutting. This would enable comprehensive analyses of the particulate burden, composition and biological viability. The method was applied to compare the electrosurgical smoke generated (in the absence of any evacuation mechanism) with the aerosolized/airborne by-products generated by ultrasonic and high-speed cutting, from bone and liver tissue cutting. We report a wide range of particle sizes $(0.93$ $806.31 \mu \mathrm{m}$ for bone, $0.05-1040.43 \mu \mathrm{m}$ for liver) with $50 \%$ of the particles being $<2.72 \mu \mathrm{m}\left(\sim \mathrm{PM}_{2.5}\right)$ and $90 \%$ being $<10 \mu \mathrm{m}\left(\mathrm{PM}_{10}\right)$. EDX and biochemical analysis reveal components of biological cells and cellular metabolic activity in particulate from liver tissue cut by electrosurgery and ultrasonic cutting. We show for the first time however that bone saws and ultrasonic cutting do not liberate viable cells from bone.
\end{abstract}

Keywords-Surgical smoke, Airborne particulate, Aerosol, Plume, Dissection, Tissue ablation, Particle sizing, Laser diffraction, SEM, EDX.

Address correspondence to Laoise M. McNamara, Mechanobiology and Medical Device Research Group (MMDRG), Biomedical Engineering, National University of Ireland Galway, Galway, Ireland. Electronic mail: laoise.mcnamara@nuigalway.ie

\section{INTRODUCTION}

Electrosurgery creates a by-product known as "surgical smoke" (also referred to as cautery smoke, surgical plume, diathermy plume, smoke plume or plume). This smoke emanates from the surgical cut site creating a potent odour, as well as reducing visibility for the surgeon. It disperses throughout the operating theatre unless some form of evacuation mechanism is in place and there is evidence that it carries hazards related to particulate burden, chemical composition and biological activity. ${ }^{65}$

Understanding of surgical smoke composition can be limited by the restricted size range that ambient particulate measuring devices can characterize, typically having resolutions up to $\sim 10 \mu \mathrm{m}$. There is also an inability with these devices to readily access analysed particulate for further analysis e.g. SEM/ TEM. Depending on the analytical techniques used, surgical smoke has been reported to contain particles of varying size, e.g. cascade impaction $(0.2-9.8 \mu \mathrm{m}$, $0.1-10 \mu \mathrm{m}),{ }^{13,50}$ condensation particle counters $(0.01-$ $1 \mu \mathrm{m}),{ }^{4,9}$ and electrical low pressure impactors $(0.007-10 \mu \mathrm{m}){ }^{35}$ Particles outside the ranges of a particular technique cannot be detected and this may skew the reported size distribution in any single study. An approach is thus required to enable particle collection from surgical cutting to facilitate particle sizing as well as morphological, elemental composition and biological activity assessment of the particulate.

Chemicals that are potentially toxic, carcinogenic, neurotoxic and mutagenic (such as acrylamide, 
acetaldehyde, formaldehyde, benzene, cyclohexanone, toluene, ethylbenzene, and xylene) have been identified in surgical smoke. ${ }^{1,14,23,29,31,39,62}$ Inhalation of low levels of surgical smoke in rats has been associated with pathological events, such as emphysema, interstitial pneumonia as well as bronchiolar hypertrophy and hyperplasia. These pathologies are correlated with the duration of smoke exposure and number of consecutive days exposed. . $^{5,6}$

Surgical smoke may possibly serve as a transportation mechanism for harmful biologically active material during surgery (cancerous cells, viruses). This is particularly topical at the present time during the COVID-19 pandemic, when exposure to aerosol is hypothesized to be a mode of transmission for SARSCoV-2. ${ }^{10}$ Aerosol generating procedures, any medical procedure that can induce the production of aerosols of various sizes, ${ }^{33}$ have come into focus as infection prevention and control advice is sought after by healthcare workers. Viable cells are contained in nonairborne surgical cutting by-products such as bone dust and chips, ${ }^{18,41,54}$ but conflicting research exists regarding whether surgical smoke contains viable biological agents. For example viable melanoma cells were demonstrated in plume created by the electrocautery of mouse melanoma cells. ${ }^{24}$ However one study found no viable cells in the smoke generated by electrosurgery during tumour dissection ${ }^{49}$ and more recently, it was reported that no viable $\mathrm{SCC} 7$ mouse cancer cells were identified in smoke generated by either electrosurgery or radiofrequency ablation. ${ }^{32}$

Viable viruses have been identified in surgical smoke which supports the possibility of viral transmission through surgical smoke. ${ }^{26,27,30}$ Laryngeal papillomas in a surgeon who had administered laser therapy to patients with anogenital condylomas were reported in a study to have been caused by inhaled human papillomavirus virus particles. ${ }^{30}$ In another study, intact viral DNA was identified in the plume collected during carbon laser therapy of papillomavirus-infected verrucae $^{28}$ and subsequently transmission of disease and infectivity was confirmed by inoculation of the laser plume into the skin of calves. ${ }^{27}$

Surgical smoke is a term commonly associated with electrosurgery and cautery devices. However, airborne by-product can also be generated by ultrasonic aspirators/scalpels, high speed drills, burrs and saws (amongst others). For ultrasonic aspirators, one investigation of the aerosolized by-product showed that no viable cells are liberated during tumour dissection, ${ }^{49}$ whereas it was recently reported that ultrasonic scalpels aerosolize viable cells but the study in question involved the cutting of cultured cancer cells rather than bulk tissue. ${ }^{32}$ Aerosolized by-product collected from the ultrasonic scalpel of cultured cancer cells were injected subcutaneously into 5-week-old male $\mathrm{C} 3 \mathrm{H}$ mice and an increase in tumour prevalence has been observed at 2 weeks. ${ }^{32}$ A study investigating vapour from bone cutting instruments added the aerosol from blood containing HIV-1 to MT-2 cells which became HIV-1 positive as a result. ${ }^{34}$ The same study observed no HIV-1 infected MT-2 cells from electrocautery of blood containing HIV-1. ${ }^{34}$

Electrosurgical smoke has previously been analysed to study particle production generated during electrosurgery for soft tissues such as muscle, liver and fat. ${ }^{35}$ However, the physical characteristics of the particulate generated during bone tissue cutting has never been investigated and any influence that the cutting modality has on particle size is not yet fully understood. Although it has been reported that cell viability is altered if directly subjected to mechanical stimuli and/or exposure to temperature,${ }^{15-17}$ how the cutting mechanism and temperature governs the viability of cells within aerosolized particles is not yet fully understood .

The objectives of this study are to (1) design a means of capturing smoke/particulate from surgical cutting thus enabling (2) a thorough examination of particulate size, morphology, elemental composition and biological viability and (3) a comparison of different cutting devices and tissues.

\section{MATERIALS AND METHODS}

\section{Tissues and Cutting Modalities}

Bovine and porcine bone, and lamb liver samples used in particle sizing experiments were sourced from an abattoir in Middleton, Cork, Ireland. The bovine metatarsal and lamb liver samples for the metabolic activity experiments were obtained fresh on day of slaughter from an abattoir in Athenry, Galway, Ireland. They were stored at $4{ }^{\circ} \mathrm{C}$ in phosphate buffer saline (PBS) $+4 \%$ anti-mycotic solution until use. The experiments were carried out within $24 \mathrm{~h}$ of slaughter and little animal-to-animal variation was observed in the samples. For the SEM/EDX analysis five tissue samples were analysed per cutting condition. For the particle size distribution experiments three tissue samples were analysed per cutting condition. For the metabolic activity and DNA experiments five samples tissue samples were analysed per cutting condition.

Three different cutting modalities were used in this study-monopolar electrosurgery (Neptune E-SEP Pencil, Stryker), ultrasonic cutting with the relevant bone/soft-tissue specific tip (Sonopet Ultrasonic Aspirator, Stryker), and a sagittal saw (RemB 
handpiece with Microsag Blade, Stryker). The three modalities differ in their mechanism of cutting and were chosen to provide information on the aerosol generated in different surgical procedures. It is important to note that no smoke evacuation was used with the E-SEP electrosurgical pencil or during the other experiments. The electrosurgical power setting of $60 \mathrm{~W}$ was chosen as "cut mode" has been reported to be effective between $50 \mathrm{~W}$ and $80 \mathrm{~W}^{2}$ and it sufficiently cut through liver tissue even when eschar fouled the stainless-steel blade electrode. The electrosurgical generator (ConMed System 5000) used had a dynamic response technology in-built, which monitors current and voltage 450,000 times per second and can change in real time (less than $10 \mathrm{~ms}$ ) to ensure the correct current is applied to the tissue to maintain the selected power level. For ultrasonic cutting, the power setting used was $80 \%$ with $50 \%$ suction and $18 \mathrm{ml} / \mathrm{min}$ irrigation. The sagittal blade speed was controlled by a foot pedal and tissue samples were weighed before and after cutting. The operator of the cutting instruments was an engineer trained in their usage of these instruments by the manufacturers. Cutting was carried out in 5-min periods, with short stoppages ( $\max 10 \mathrm{~s}$ ) being made when necessary to allow for tip/blade cool down.

\section{Electrostatic Particle Capture and Imaging}

\section{Electrostatic Precipitation}

Electrostatic precipitation is a technique that removes fine particles from a flowing gas using the force of an induced electrostatic charge, it is used in various industrial applications including power generation and incineration facilities to filter exhaust fumes prior to venting to the atmosphere to reduce emissions. ${ }^{37,38,51,67}$ In the present study, particles were collected by electrostatic precipitation using a custom-built wire-plate electrode system (Fig. 1). In the experiments, a high voltage was applied between two parallel rectangular indium-tin-oxide (ITO) conductive coated films onto which particles were collected and grounded copper wires were used as discharge electrodes. These were placed in a 3D printed housing, shown in Fig. 1, printed using VeroWhitePlus resin (Stratasys) with a Polyjet 3D printer (Stratasys Connex 500), which uses UV cured resins. High voltage between ITO films and wires create an ionised atmosphere (corona discharge) between them. Particles passing through this ionised atmosphere pick up charge and are subject to a transverse electrostatic force that pulls them towards the collection surface. The experimental setup also included a stage for tissue cutting positioned below the particle collection area and a variable speed fan (SilverStone SST-FW121, 12 V DC, speed: 800-2000 rpm, airflow: $0.006-0.015 \mathrm{~m}^{3} \mathrm{~s}^{-1}$ ) to induce the plume to flow vertically. The control module incorporating a HV power supply is used to set voltage and fan speed with current levels also being monitored. The voltage difference across the ITO films and wires used during experiments was $17.5 \mathrm{kV}$ to ensure particle collection while remaining below the voltage level at which arcing would occur between the ITO films and copper wires.

\section{Scanning Electron Microscopy and Energy-Dispersive $X$-ray}

For scanning electron microscopy (SEM) and energy-dispersive X-ray spectroscopy (EDX) analyses, smoke/particulate collected via electrostatic precipitation from bone and liver cutting were mounted to sample stubs using double sided adhesive carbon discs and sputter coated with gold. Sample analysis was then performed using a Hitachi S-4700 SEM (magnification range: from $\times 30$ to $\times 500$, accelerating voltage range: from $0.5 \mathrm{keV}$ to $30 \mathrm{keV}, 2.5 \mathrm{~nm}$ resolution at $1 \mathrm{kV}$; $1.5 \mathrm{~nm}$ resolution at $15 \mathrm{kV}$ ) with EDX at NUI Galway. Images taken using SEM were post-processed using ImageJ software for size analysis and creation of size distributions.

\section{Filtration Particle Capture and Physical/Biochemical Analysis}

\section{Impingement Filtration System}

Collection of smoke and particulate was carried out using the impingement filtration setup, shown in Fig. 2, to allow the size distribution of particles to be investigated. A gas washing bottle (Duran ${ }^{\mathrm{TM}}$ Essay Drechsel, Fisher Scientific, UK) was connected to a vacuum pump set to a suction pressure of $250 \mathrm{mmHg}$. Airborne by-products from porcine femurs and lamb livers were aspirated into HPLC grade water for particle distribution analysis $(n=3)$ and into sterile PBS for Alamar Blue assays and DNA quantification $(n=5)$.

\section{Particle Size Distribution Analysis}

In order to investigate size distribution of particles, samples from the impingement filtration experiments were inputted into a laser diffraction system (Malvern Mastersizer 3000, particle sizing range: $0.01-3500 \mu \mathrm{m}$ ). The Mastersizer was equipped with a small volume Hydro SM wet dispersion unit and HPLC grade water was used as the dispersing medium. Samples were homogenised throughout the measurement using the dispersion unit's in-built stirrer (1500 rpm). Measure- 

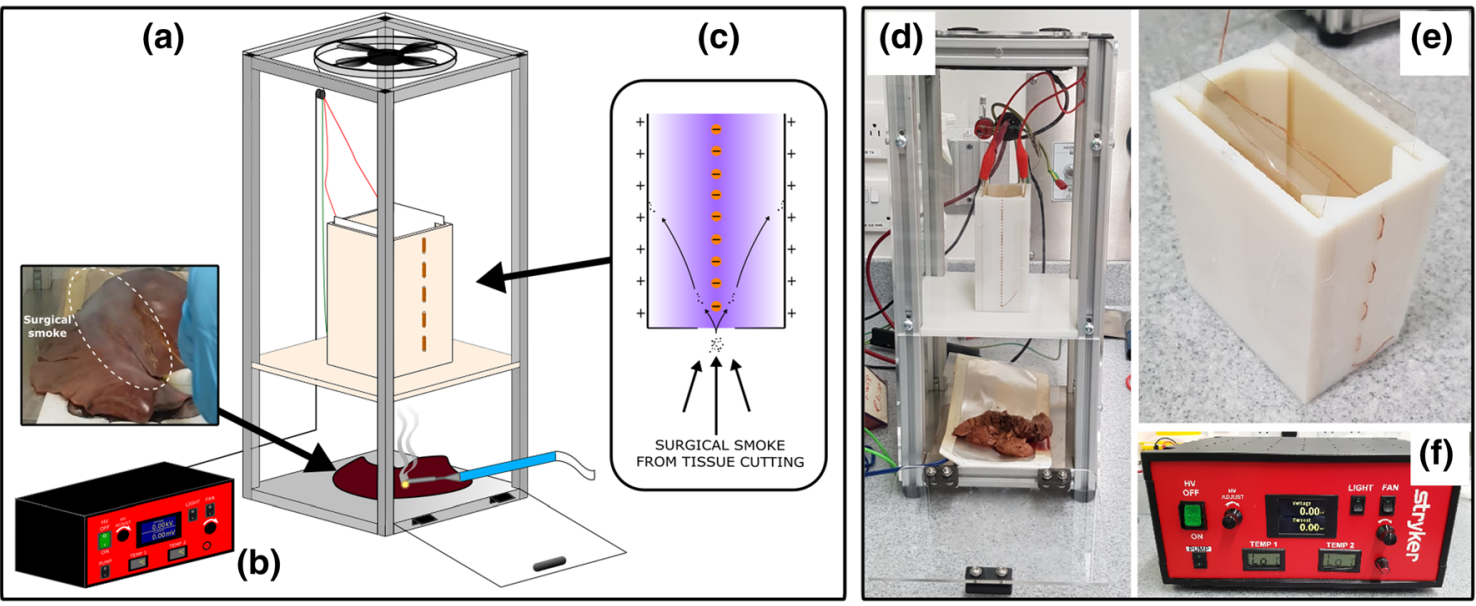

FIGURE 1. Schematic diagram of electrostatic precipitation experimental set up. (a) frame structure fully enclosed with clear Perspex houses the cutting and electrostatic precipitation collection area. The fan is positioned on the top of this structure to draw up the surgical smoke/particulate. (b) Control module for the HV power supply and fan (operated at speed of $2000 \mathrm{rpm}$ and airflow of $0.015 \mathrm{~m}^{3} \mathrm{~s}^{-1}$ for the duration of experiments). Current levels also monitored. (c) Diagram of electrostatic precipitation within the device. Image of the frame structure (d), electrode holder (e) and control module (f).

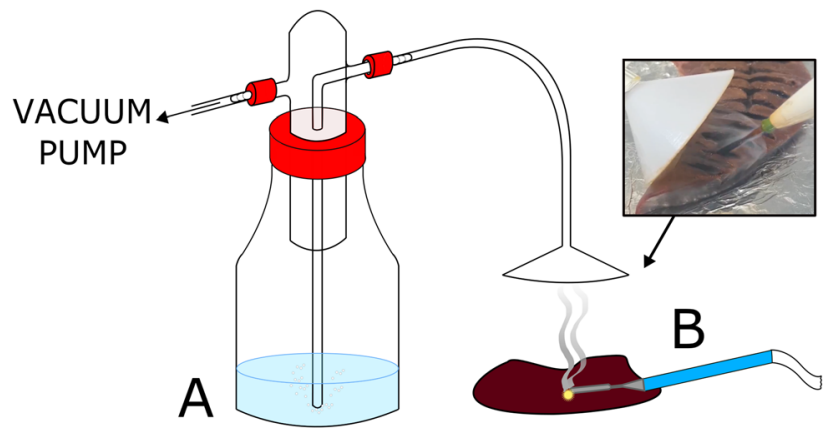

FIGURE 2. Schematic diagram of impingement filtration experimental set up. Gas washing bottle (a) is connected to a vacuum pump and used to aspirate airborne by-product from the cut site (b) into HPLC grade water or PBS depending on analysis.

ments were repeated 10 times and the system's software ensured variability was within ISO limits (ISO 13320: Particle size analysis_-Laser diffraction methods).

\section{Metabolic Activity and DNA Content}

Fresh from slaughter bovine metatarsal bone and lamb livers were used to investigate metabolic activity and DNA content of collected smoke and aerosolized particulate. Cutting was performed on five metatarsal bones and five livers within $24 \mathrm{~h}$ of sacrificing of animals. The assays were performed immediately after cutting. Collection of the particulate was carried out using the impingement filtration process (described above) in a sterile laminar flow hood. Fifty millilitres of sterile PBS was used as the collection medium and once surgical smoke had been aspirated, the sample was homogenised and split so that one half of the sample could be analysed using an Alamar Blue assay and the other half could be used for DNA quantification using a Hoescht DNA assay.

After the samples were split, they were centrifuged at $40,000 \mathrm{rpm}$ for $10 \mathrm{mins}$. Analysing metabolic activity, each sample was reconstituted in PBS and subsequently Alamar Blue dye (Invitrogen) was added (10\% Alamar Blue, 90\% sample). The samples were then incubated $\left(37{ }^{\circ} \mathrm{C}, 5 \% \mathrm{CO}_{2}\right)$ for $4 \mathrm{~h}$ after which absorbance was read with a microplate reader (Synergy HT, BioTek) at wavelengths of $570 \mathrm{~nm}$ and $600 \mathrm{~nm}$. For DNA analysis, supernatant from samples were removed and samples were resuspended in lysis buffer. Hoescht 33258 (Sigma) working dye solution was prepared by adding 10x Hoescht buffer (6.05 g Tris, $1.85 \mathrm{~g} \mathrm{Na}_{2}$ EDTA \& $29.20 \mathrm{~g} \mathrm{NaCl}$ in $\mathrm{dH}_{2} \mathrm{O}$ ) to $\mathrm{dH}_{2} \mathrm{O}$ and $1 \mathrm{mg} \mathrm{ml}^{-1}$ Hoescht dye and protected from light. In a black bottom 96-well-plate, working dye solution was added to $20 \mu \mathrm{l}$ of sample in triplicate. Fluorescence was measured at an emission of $460 \mathrm{~nm}$ and excitation of $365 \mathrm{~nm}$ was measured with a microplate reader (Synergy HT, BioTek). DNA content was determined by using a standard curve, created using a known amount of purified calf thymus DNA. A student's t-test was used to assess statistical significance of the difference between cutting conditions. All data in this study was processed using Matlab and GraphPad Prism.

\section{RESULTS}

The electrostatic precipitation and the impingement filtration systems were able to collect airborne particles from surgical cutting, see Figs. 3, 4, and 5. This allowed the particulate collected from bone and liver cutting to be 
(a)

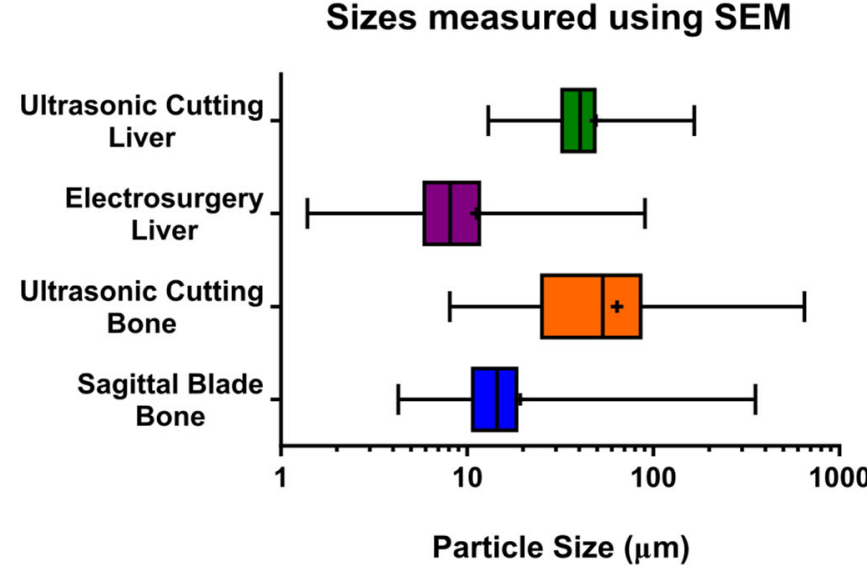

(b)
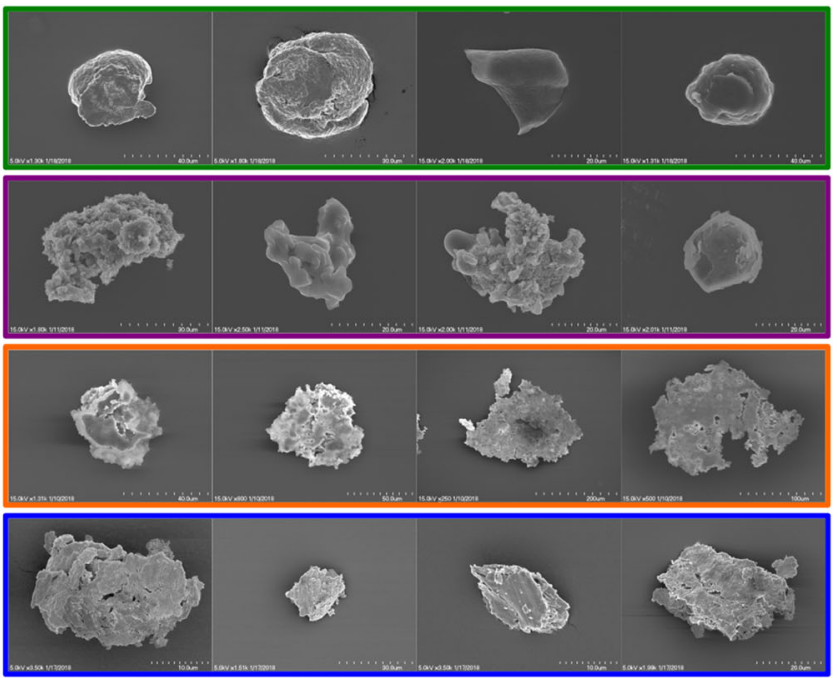

FIGURE 3. (a) Particle range for each cutting condition shown in graph. (b) SEM images of collected particles for each cutting condition. For each cutting condition five tissue samples were used $(n=5)$. Note scale bars are not uniform across all SEM images, but each scale bar is provided within the relevant image.
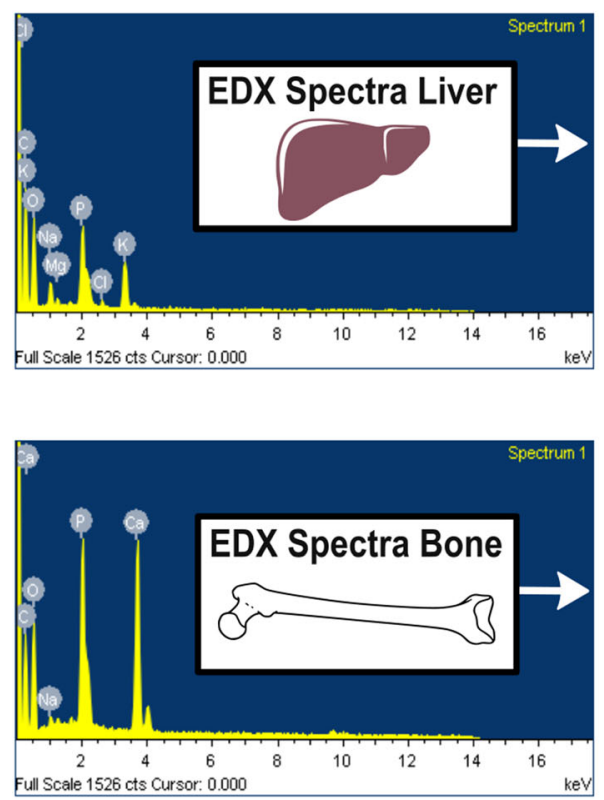

(a) Electrosurgery

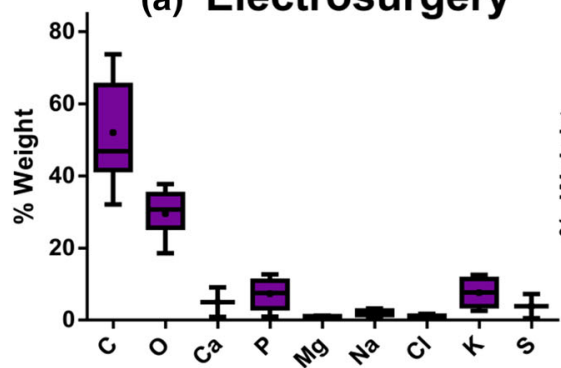

(c) Sagittal Blade

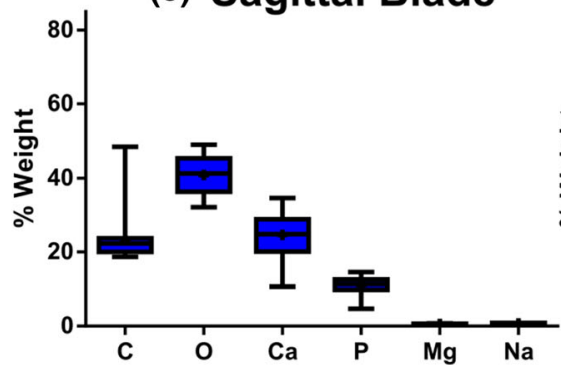

(b) Ultrasonic Cutting

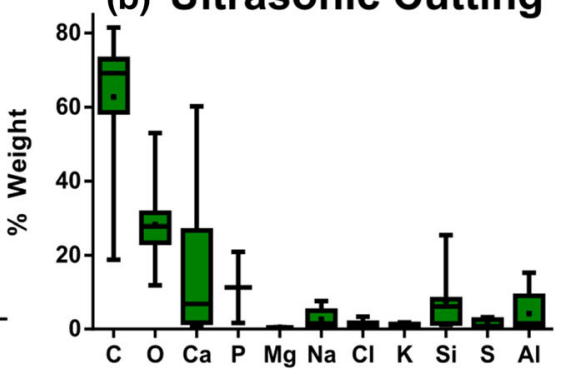

(d) Ultrasonic Cutting

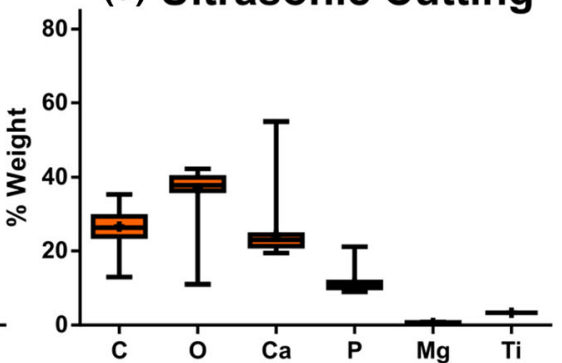

FIGURE 4. EDX spectra of particulate collected using electrostatic precipitation. Shown left are two examples of spectra obtained with boxplots on right describing the elemental composition of all particles analysed during (a) electrosurgery of liver, (b) ultrasonic cutting of liver, (c) sagittal blade cutting of bone and (d) ultrasonic cutting of bone.

imaged, their size distribution and elemental composition determined, and the cellular assays performed.

\section{Imaging}

Particles collected using electrostatic precipitation were subjected to SEM analysis. Figure 3 shows SEM images of bone particles from ultrasonic and sagittal saw cutting, and liver particles from ultra- sonic cutting (soft-tissue-tip) and electrosurgery. Image analysis of 3965 surgical smoke particles revealed a wide range of particle size, with smallest and largest particles measured being 8.1 and $694.5 \mu \mathrm{m}$ for bone and 1.4 and $166.1 \mu \mathrm{m}$ for liver, see Fig. 3. Bone particulate exhibited a flake-like morphology whereas liver particulate was highly amorphous. Near-spherical particles were sometimes seen in the liver experiments (see Fig. 3). 

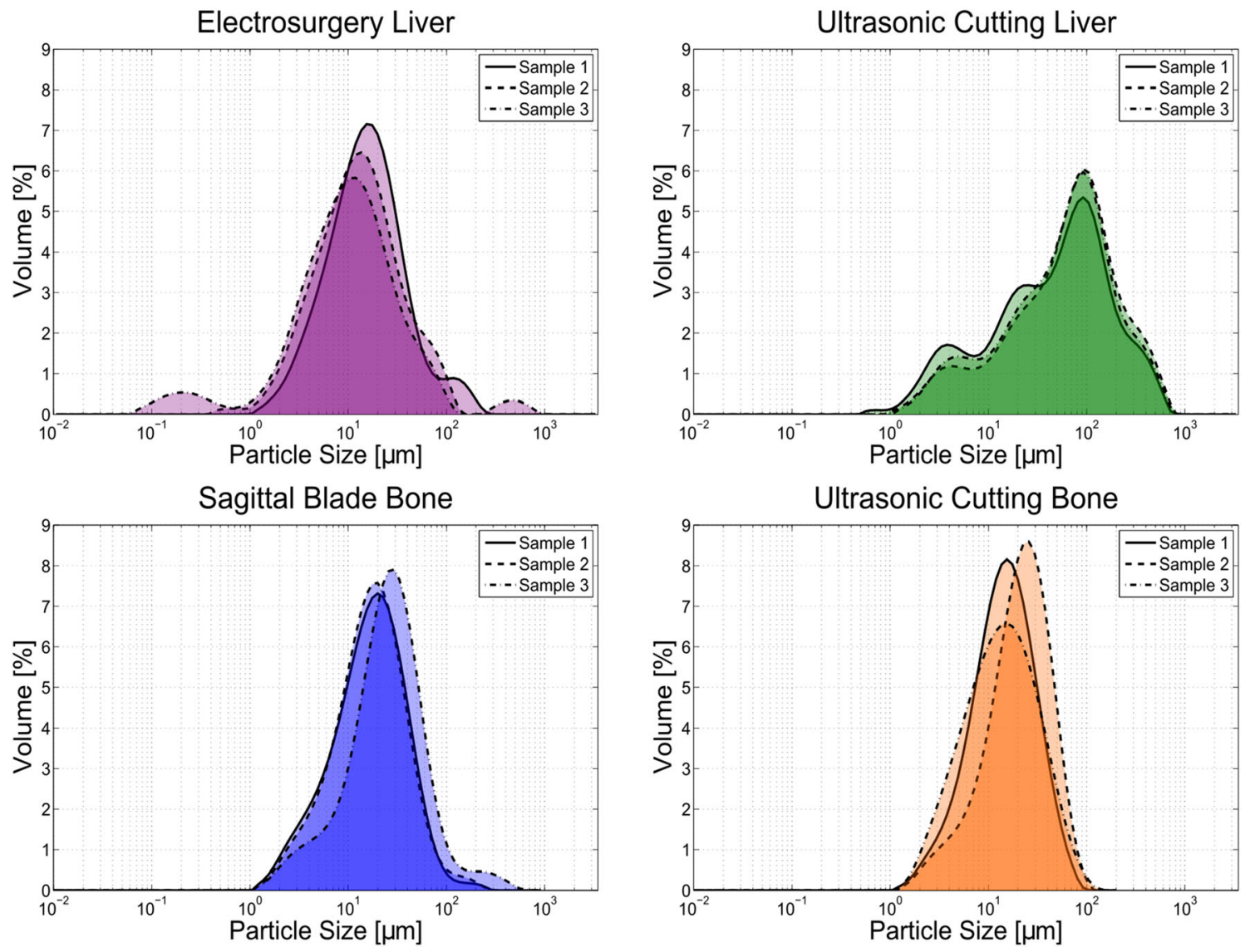

FIGURE 5. Size distributions by volume (\%) of particulate created during electrosurgery of liver, ultrasonic cutting of liver, sagittal saw cutting of bone and ultrasonic cutting of bone. Size distributions are obtained using laser diffraction (Mastersizer 3000). Cutting was carried out on three different samples $(n=3)$ with each device and each plot shows the 3 particle-size distributions. D-values for the above plots are shown in Table 1.

\section{Elemental Analysis}

EDX spectra were obtained for 90 particles (ultrasonic cutting of bone $(n=21)$, sagittal saw cutting of bone $(n=20)$, ultrasonic cutting of liver $(n=27)$ and electrosurgery of liver $(n=22))$. As expected, the EDX spectra (Fig. 4) showed carbon and oxygen to be most prominent, with lower varying levels of sodium, magnesium, phosphorus, chlorine, potassium, silicon, calcium, sulfur also being observed. Titanium was noted in one sample, attributed to wear of a tool tip.

\section{Physical Analysis of Filtered Particles}

The particles collected by the impingement filtration system were suspended in HPLC grade water and analysed in the Mastersizer particle size analyser. The instrument calculated, using Mie scattering theory, that the refractive index (RI) and the absorption index (AI) of the liver particles (electrosurgery and ultrasonic cutting) were 1.63 and 0.01 respectively. For the bone particles (ultrasonic cutting and sagittal blade) the RI and AI were 1.8 and 0.01 respectively. Figures 5 and 6 shows the size distributions by percentage volume, and size distributions by percentage number, for all cutting conditions. Table 1 describes the percentile information for the distribution (D-values) of particles within the samples in Figs. 5 and 6. The aerosolized mist created by ultrasonic cutting contained larger particles (Volumetric Mass Median Diameter (MMD) was $71.8 \mu \mathrm{m})$ than the smoke/plume of the other cutting modalities $(<20 \mu \mathrm{m})$. In all cutting experiments, $90 \%$ of particles created were $\leq 6.27 \mu \mathrm{m}$ and $10 \%$ of particles were $\leq 1.59 \mu \mathrm{m}$.

\section{Biochemical Analysis of Filtered Particles}

Directly after cutting, there was a significant difference $(p \leq 0.01)$ in metabolic activity between the particulate from ultrasonic cutting of liver and the particulate from electrosurgery of liver. Ultrasonic cutting of liver showed approximately 7-times higher metabolic activity than that of electrosurgery of liver (Fig. 7). No metabolic activity was seen in the partic- 

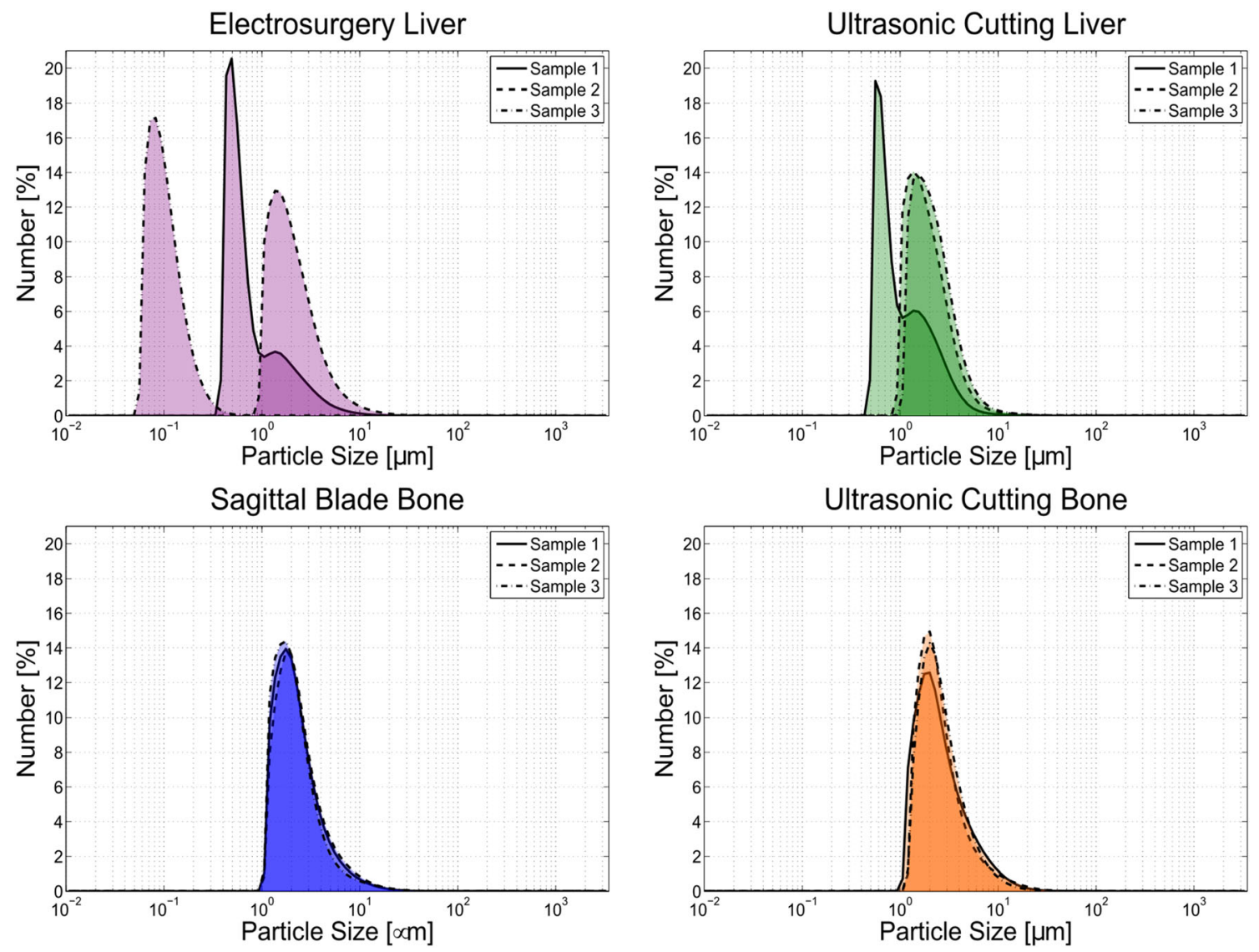

FIGURE 6. Size distributions by number (\%) of particulate created during electrosurgery of liver, ultrasonic cutting of liver, sagittal saw cutting of bone and ultrasonic cutting of bone. Size distributions are obtained using laser diffraction (Mastersizer 3000). Cutting was carried out on three different samples $(n=3)$ with each device and each plot shows the 3 particle-size distributions. D-values for the above plots are shown in Table 1.

TABLE 1. D-values showing the 10th, 50th and 90th percentile reading for average $\%$ volume and $\%$ number distributions shown in Figs. 4 and 5.

\begin{tabular}{|c|c|c|c|c|c|c|}
\hline \multirow[b]{2}{*}{ Cutting condition } & \multicolumn{3}{|c|}{ Volume (\%) } & \multicolumn{3}{|c|}{ Number (\%) } \\
\hline & $\mathrm{D}(10)(\mu \mathrm{m})$ & $\mathrm{D}(50)(\mu \mathrm{m})$ & $\mathrm{D}(90)(\mu \mathrm{m})$ & $\mathrm{D}(10)(\mu \mathrm{m})$ & $\mathrm{D}(50)(\mu \mathrm{m})$ & $\mathrm{D}(90)(\mu \mathrm{m})$ \\
\hline Electrosurgery liver & 3.42 & 12.60 & 44.80 & 0.60 & 0.95 & 2.52 \\
\hline Ultrasonic liver & 7.05 & 71.80 & 276.00 & 1.11 & 1.73 & 3.76 \\
\hline Ultrasonic bone & 5.32 & 16.60 & 42.20 & 1.59 & 2.72 & 6.27 \\
\hline Sagittal blade bone & 5.70 & 19.90 & 54.00 & 1.47 & 2.35 & 5.44 \\
\hline
\end{tabular}

$\mathrm{D}(50)$ is also known as the Mass Median Diameter (MMD).

ulate from sagittal blade cutting or ultrasonic cutting of bone.

\section{DISCUSSION}

In this study we investigated the contents of surgical smoke (electrosurgery) and the airborne particulate generated by other surgical instruments (ultrasonic cutting and bone sawing). We investigated these byproducts using a specially designed electrostatic precipitation collection device, which allowed the analysis of physical and biological properties. Using this novel collection technique, we have shown that the particle sizes and morphology varies greatly and depends on the composition of the tissue being cut and the type of cutting modality. The results indicate that the equipment used to measure particle size in previous studies 


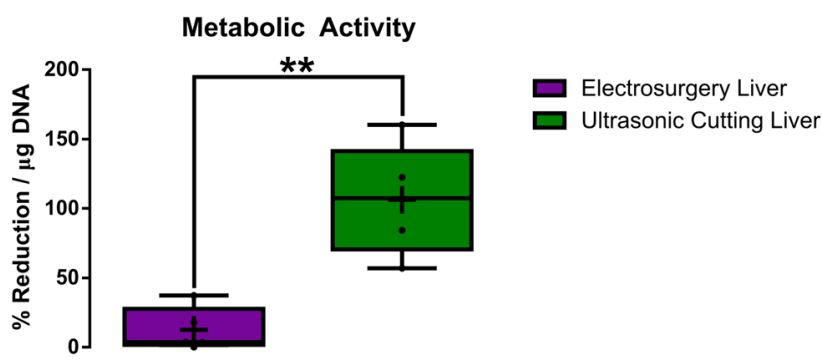

FIGURE 7. Metabolic activity standardised to $\mu \mathrm{g}$ of DNA. Ultrasonic cutting of liver showed approximately 7-times higher metabolic activity than that of electrosurgery of liver $\left({ }^{\star *} p \leq 0.01\right)$. No metabolic activity was seen in the particulate from sagittal blade cutting or ultrasonic cutting of bone. 5 samples were used per cutting condition $(n=5)$.

has not been able to see the full range of particle sizes, and this range has been underestimated to date. EDX and biological assays confirm that the particulate from surgical cutting contains biological material and that some cells are viable from liver tissue cut by electrosurgery and ultrasonic cutting. The same assays also show that airborne bone particulates do not contain viable cells.

There are limitations regarding the collection techniques used in this study that require consideration. Firstly, the environment where experimentation was carried out was an idealised laboratory situation and may not reflect a health care professional's surgical environment. The inbuilt smoke evacuation on ESEP pencil was not employed, the instruments were put cutting for (unrealistically long) 5-min periods and airborne particulate was actively drawn into the collection mechanism using suction a few centimetres from the cut site. In operating theatres, local exhaust ventilation (LEV) systems, such as smoke evacuators, unidirectional displacement flow (UDF) or laminar flow, draw particulate away from the surgeon. The distance particles can travel in operating theatre conditions is unknown, but large particulates $(>10 \mu \mathrm{m})$ have larger terminal falling velocity and inertia, relative to smaller particulate that might be easily carried in weak air streams, which may impact how far they can travel within the operating environment. ${ }^{36} \mathrm{~A}$ different particle distribution might be observed if particulate was collected where a surgeon or theatre staff member would be located. Furthermore, although the time from animal sacrifice to experimentation was minimised, in-vivo blood supply may also affect the particulate aerosol generation. Secondly, the operator of the cutting devices was a trained engineer, who cut each sample with as similar and uniform a technique as possible, but pressure applied was not measured and variations in the by-product produced due to operator (i.e. surgeon) variability is unavoidable. However, such variability would exist in surgical practice where monitoring pressure is not commonly implemented. It is important to note in the electrosurgery case, the tissue sample (liver) impedance in this simulated bench testing may differ from the patient whole body impedance encountered in practice. Although the generator (ConMed 5000) used is capable of delivering consistent output power over a range of resistances for the pure cut mode, ${ }^{12}$ the delivered energy may not be equivalent to that arising during a real surgery, but may be considered representative at the energy level tested. Furthermore, the study was limited to bone and liver tissue using specific cutting modalities and so the results may not be representative of all tissues or cutting devices. For example, in electrosurgery, monopolar electrodes with different geometries (such as blade, needle, loop and ball) and bipolar instruments will interact differently with tissue. Finally, while it might be expected that the temperature is a direct result of the heating effect, tissue-energy interactions can be complicated for surgical tools, in particular radiofrequency tools, and the mechanisms underlying the particulate generation are not fully understood. Future studies could investigate further the relationship between the energy mechanism and the nature of the particulate generated.

Electrostatic precipitation is widely used to collect aerosol particles. The mobility of a particle is a function of particle size therefore collection efficiency in short transit times can be affected. ${ }^{40}$ In this study, the collection efficiency was not quantified as particle precipitation was deemed adequate visually. This type of process also creates the by-product Ozone $\left(\mathrm{O}_{3}\right)$. Our experiments were performed in a well-ventilated lab space and duration closely monitored. The chamber where ionisation and collection occur is relatively small compared to large electrostatic precipitators for the likes of industrial applications. As previous literature has used similar methods to collect and analyse particulate, the effects are assumed to be small if any on the results. ${ }^{8}$ For both collection techniques implemented in this study, some particulate may escape naturally away from these inlet areas and not be collected, as for any collection device (during the experiments visual inspection of the aerosol suggested that most entered the collection devices, Figs. 1 and 2). Our techniques did not allow for investigation of toxic and carcinogenic properties of the airborne by-products. Future studies should investigate whether production of these chemicals is cutting tool and/or tissue dependent.

It is interesting that our results report that the spectrum of particle sizes within surgical smoke has been underestimated to date. In our experimental setup using electrostatic precipitation, particles experience lower non-perpendicular impaction velocities com- 
pared to that of an impaction or cyclonic methods of particle separation. ${ }^{3}$ Therefore, particles experience less force and a lower probability of deformation upon deposition. Furthermore, our results are in good agreement with previous in situ measurements of particle size and fuel soot shape (with light scattering, or with electrostatic collection plus transmission electron microscopy), ${ }^{8}$ which suggests morphology is not altered by electrostatic collection methods.

In this study, collected particulate morphology determined via SEM showed amorphous fragments produced in all cutting scenarios with round particles demonstrated in the liver particulate (with electrosurgery and ultrasonic cutting). This is in agreement with previous SEM studies that looked at the effect of electrocautery on animal tissue and human tissue from laparoscopic surgeries, ${ }^{13}$ ultrasonic cutting on porcine psoas muscle ${ }^{65}$ and electrosurgery on human tissue from breast reduction and knee amputation surgery. ${ }^{43}$ Homogenous spheres $(\leq 1 \mu \mathrm{m})$ were identified in surgical smoke by a cascade impactor. ${ }^{13}$ In this study, we see similar spherical particulate; however, it is generally $\sim 25 \mu \mathrm{m}$ or larger. To our knowledge no previous study has investigated the particulate generated from bone cutting, which we found in this study to contain irregular morphologies but also tended to exhibit flakelike particulate. The smallest and largest particles measured using SEM were 8.1 and $694.5 \mu \mathrm{m}$ for bone and 1.4 and $166.1 \mu \mathrm{m}$ for liver.

The EPA (United States Environmental Protection Agency, www.epa.gov) classifies airborne particles according to their aerodynamic diameter: $\leq 10 \mu \mathrm{m}$ diameter particles $\left(\mathrm{PM}_{10}\right)$ are inhalable and the coarse fraction $(2.5-10 \mu \mathrm{m})$ will deposit them in the respiratory tract which are removed by mucociliary clearance. $^{40}$ Insoluble fine particulate matter, $\leq 2.5 \mu \mathrm{m}$ diameter particles $\left(\mathrm{PM}_{2.5}\right)$, can reach the alveolar region of the lung where clearance occurs through phagocytosis by alveolar macrophages, which may induce inflammatory and pro-thrombotic responses. ${ }^{55}$ Medical masks are tested for bacterial filtration efficiency from inside to outside, ${ }^{47}$ however medical masks have been shown to be penetrated by particles $9 \mu \mathrm{m}$ is size and they are susceptible to leakage around the face seal. ${ }^{25,52}$ Surgical N95 respirators and High-Efficiency Particulate Air (HEPA) filters remove particles larger than $0.3 \mu \mathrm{m}$ and Ultra-Low Particulate Air (ULPA) filters (used in surgical smoke evacuators) remove particles larger than $0.12 \mu \mathrm{m} .{ }^{25}$

Generally, all airborne particulates are harmful to inhale, and the size only affects the severity. Rats exposed to filtered exhaust surgical smoke (particle size $<0.5 \mu \mathrm{m}$ ) demonstrated pathological effects such as emphysema, interstitial pneumonia, and bronchiolar hypertrophy and hyperplasia. However, in the pres- ence of an ULPA filter, the effects appeared less severe and rat lungs appeared unaffected and similar to control. ${ }^{5}$ The present study identified that $90 \%$ of particles in surgical smoke are within the $\mathrm{PM}_{10}$ classification for all cutting conditions, with electrosurgery of liver having almost $90 \%$ of particles under $\mathrm{PM}_{2.5}$ classification $(2.52 \mu \mathrm{m}$, Table 1). Furthermore, for all cutting conditions, $50 \%$ of particles fall under $\mathrm{PM}_{2.5}$ classification except for ultrasonic cutting of bone which was just above the limit $(2.72 \mu \mathrm{m}$, Table 1$)$. The sizes of particles identified in this study would suggest that correct implementation of a smoke evacuator equipped with a HEPA or ULPA filter would be able to remove more than $90 \%$ of all particulates created. Although shape and morphology of particles was investigated in this study, further studies are required to determine whether these are contributing factors to adverse health.

Electrosurgery on lamb muscle tissue has been shown to produce particles with an upper range of $1 \mu \mathrm{m} .{ }^{21}$ Electrical low pressure impactor (ELPI) analysis of the surgical smoke from electrosurgery on porcine tissues has previously detected particles with an upper range of $10 \mu \mathrm{m} .{ }^{35}$ The larger particle sizes reported in the current study (up to $\sim 800 \mu \mathrm{m}$ for bone and $\sim 1000 \mu \mathrm{m}$ for liver) are outside the upper ranges for size previously reported..$^{4,9,13,21,35,50}$ This may be due to the fact that the electrostatic precipitation collection technique did not limit the size of particles collected, whereas aerodynamic particle sizers, cascade impactors and ELPIs limit the detectable sizes to within $0.05-30 \mu \mathrm{m}$ (this is due to the technical challenges presented by measuring particles in low concentrations that have large inertia and gravitational velocities). ${ }^{40}$ Laser diffraction has been used in a previous study to analyse surgical smoke from electrosurgery of uterine tissue. ${ }^{22}$ The Mastersizer 3000 used in the present study uses laser diffraction and is capable of sizing particles within $0.01-3500 \mu \mathrm{m}$, and also continually circulates the sample to avoid sedimentation effects. Size distributions obtained using the Mastersizer 3000 aligned well to the particle sizes seen in the SEM analysis of particulate (Figs. 3, 5 and 6).

Here we report for the first time that airborne particulate from surgical cutting contains components of biological cells and these are metabolically active for liver tissue cut by electrosurgery and ultrasonic cutting. We also report that the airborne plumes generated from the mechanical and ultrasonic cutting of bone contained no viable particulate. EDX spectra obtained in this study are comparable to other work that has analysed surgical smoke particles using EDX from electrosurgery on human tissues with carbon, oxygen sodium, chlorine, magnesium, calcium, and potassium all being present. ${ }^{13,57}$ EDX information we obtained 
from surgical smoke particulate is consistent with structural components of biological cells ${ }^{61}$ (rich in carbon and oxygen with also sodium, magnesium, phosphorus, chlorine, potassium, calcium, sulfur) and our metabolic analysis serves to confirm the biological activity of these particulates. Metabolic activity was significantly higher in the ultrasonic cutting of liver than all other cutting scenarios. Ultrasonic cutting of liver also has a larger $\mathrm{D}(90)$ value than the other two cutting modalities (Table 1) and this may play a role in metabolic activity as intact cellular material could have been aerosolized. Electrosurgery of liver has a relatively lower metabolic activity level compared to ultrasonic cutting which may be a result of the higher cutting temperature $\left(>100^{\circ} \mathrm{C}\right)^{2,45}$ causing instantaneous cell/tissue death. ${ }^{15}$ Temperature and tissue type likely play a role in the measured DNA levels within the aerosol by-products. Moreover, mode/energy level changes in any cutting device may alter the temperature of the cutting process and the amount of tissue aerosolied, and thereby affect subsequent metabolic activity and DNA content of the aerosol created.

A previous study investigating the transport of viable cells in surgical smoke performed by cutting cultured cells using an ultrasonic scalpel, electrosurgery and radiofrequency ablation, subsequently found no viable cells in either the electrosurgery or radiofrequency ablation smoke. However, viable cells were identified in all samples collected at a distance of $5 \mathrm{~cm}$ from the cut site using the ultrasonic scalpel, whereas at a collection distance of $10 \mathrm{~cm}$ for only 2 (of 25) samples contained viable cells. ${ }^{32}$ Collected aerosol, generated by ultrasonic cutting of SCC7 mouse cancer cells, was injected subcutaneously into 5-week-old male $\mathrm{C} 3 \mathrm{H}$ mice. Within 2 weeks, it was reported that 12 of 20 mice presented with tumour growth. ${ }^{32}$ During laparoscopic cholecystectomy, aerosolization of labelled red blood cells showed they implanted near trocar sites and influenced trocar site tumour recurrences. ${ }^{11}$ Another study demonstrated tumour development occurred in rats near trocar sites where gas leakage occurs. ${ }^{63}$

Aerosolization during otolaryngologic procedures has become a concern during the current COVID-19 pandemic period. Proximity to the aerodigestive tract in infected patients and instruments may lead to exposure to the virus via droplets, spatter and elevated aerosol concentrations. ${ }^{48}$ A cadaver study simulating surgical aerosolization from high speed drilling of the sphenoid rostrum and nasal beak demonstrated considerable aerosol contamination, between 6 and $30 \mathrm{~cm}$ away from the nare. ${ }^{66}$

The potential for viable material transport is said to be greater in cooler aerosols than higher temperature aerosols. ${ }^{32}$ However, this remains somewhat contro- versial as few in-vivo studies exist on the topic. Electrosurgical devices use a high frequency alternating current, which causes highly localised heating in the tissue near the active electrode ${ }^{45}$ that can exceed $100{ }^{\circ} \mathrm{C}$ leading to tissue desiccation and eschar formation. $^{2}$ A study performing monopolar electrosurgery at $40 \mathrm{~W}$ on porcine muscle measured temperature using thermocouples (verified by infrared thermometer) and reported that a peak temperature of $100.1^{\circ} \mathrm{C}$ arose at the cutting tip. ${ }^{60}$ Another study using monopolar electrosurgery, also at $40 \mathrm{~W}$, on the skin of Yucatan swine measured a peak temperature of $241^{\circ} \mathrm{C}$ at the tip by infrared thermal imaging. ${ }^{44}$ Bipolar electrosurgery has been reported to produce a peak temperature of $110^{\circ} \mathrm{C}$ at the cutting tip, using infrared thermal imaging during laparoscopic dissection in the peritoneal cavity of landrace cross pigs. ${ }^{58}$ Electrosurgical devices can be configured to favour coagulation for vessel sealing over tissue vaporization. ${ }^{7}$ Future studies should investigate the influence of the energy delivery mode on the physical characteristics of the particulate. Ultrasonic devices induce cavitation in soft tissue using mechanical vibration $(\sim 55,000 / \mathrm{s})$ and the heat they produce typically remains below $80^{\circ} \mathrm{C}$ (to minimising charring, desiccation and zone of thermal injury) but they can seal blood vessels by protein denaturation. ${ }^{2,42}$ A study of an ultrasonic scalpel used on porcine muscle demonstrated a peak temperature of $71.3^{\circ} \mathrm{C}$ at the tip when applied for $15 \mathrm{~s} .{ }^{60}$ The same study investigated the duration of cutting and power levels of electrosurgery and ultrasonic cutting and reported that peak temperatures increased with higher power setting and duration of cutting $(5,10$ and $15 \mathrm{~s}$ cutting intervals were tested). ${ }^{60}$ Ultrasonic devices for bone applications also rely on mechanical action to cut and bone cutting saws and burrs utilise rotation/ oscillation of cutting drill/blade to mechanically abrade the tissue resulting in temperatures $>50{ }^{\circ} \mathrm{C}$. This was shown in a study using infrared imaging of high-speed sawing of ovine metatarsal, which revealed a peak temperature $54.84{ }^{\circ} \mathrm{C}$ at the endosteal surface. ${ }^{17}$ However, the temperatures reported in these studies may not be directly comparable as they depend on how long the energy duration is and how the procedure is performed.

There is still limited understanding of the constituents of surgical smoke but the health risks associated with the exposure have been acknowledged by many leading organisations such as the Association of periOperative Registered Nurses (AORN), the National Institute for Occupational Safety and Health (NIOSH), the Occupational Safety and Health Administration (OSHA) and the American National Standards Institute (ANSI). ${ }^{64}$ Two US states (Rhode Island, Colorado) have already implemented legisla- 
tion requiring hospitals to adopt policies to capture and neutralize surgical smoke at the site of origin using "smoke evacuation systems" such as smoke evacuators, laser plume evacuators or LEVs, however there is no universal approach for removal of surgical smoke from the operating environment. ${ }^{46,53,59}$ The NIOSH advise LEV in conjunction with room ventilation such as UDF for surgical smoke removal (https://www.cd c.gov/niosh). A study investigating commercially available portable surgical smoke LEV systems found that the highest smoke reduction $(99 \pm 1 \%)$ was observed with maximum suction and a UDF rate of $10,500 \mathrm{~m}^{3} \mathrm{~h}^{-1}$ and with minimum suction and a UDF rate of $7500 \mathrm{~m}^{3} \mathrm{~h}^{-1}$ smoke reduction dropped to $62 \pm$ $12 \% .{ }^{56}$ AORN surveys report feedback from surgical staff that excessive noise is a deterrent for LEV use for surgical smoke removal. ${ }^{19,20}$

\section{CONCLUSIONS}

Here we report particles that lie outside the size ranges previously reported in literature for surgical smoke and aerosolized surgical cutting by-products. We report that electrosurgical smoke and, even more so, aerosolised particulate from ultrasonic cutting generated during soft tissue (liver) cutting contains metabolically active cells. To our knowledge, we report for the first time that bone saws and ultrasonic cutting do not liberate viable cells from bone. The experiments in this paper present a worst-case scenario of airborne by-production and future work should investigate the propagation of surgical smoke in more realistic (operating theatre) scenarios.

\section{ACKNOWLEDGEMENTS}

This work was supported by Science Foundation Ireland (SFI) and the European Regional Development Fund (Grant Number 13/RC/2073).

\section{REFERENCES}

${ }^{1}$ Al Sahaf, O. S., I. Vega-Carrascal, F. O. Cunningham, J. P. McGrath, and F. J. Bloomfield. Chemical composition of smoke produced by high-frequency electrosurgery. Ir. J. Med. Sci. 176:229-232, 2007.

${ }^{2}$ Alkatout, I., T. Schollmeyer, N. A. Hawaldar, N. Sharma, and L. Mettler. Principles and safety measures of electrosurgery in laparoscopy. JSLS 16:130-139, 2012.
${ }^{3}$ Amaral, S. S., J. A. de Carvalho, M. A. M. Costa, and C. Pinheiro. An overview of particulate matter measurement instruments. Atmosphere (Basel). 6:1327-1345, 2015.

${ }^{4}$ Andréasson, S. N., H. Anundi, B. Sahlberg, C.-G. Ericsson, R. Wålinder, G. Enlund, L. Påhlman, and H. Mahteme. Peritonectomy with high voltage electrocautery generates higher levels of ultrafine smoke particles. Eur. J. Surg. Oncol. 35:780-784, 2009.

${ }^{5}$ Baggish, M. S., P. Baltoyannis, and E. Sze. Protection of the rat lung from the harmful effects of laser smoke. Lasers Surg. Med. 8:248-253, 1988.

${ }^{6}$ Baggish, M. S., and M. Elbakry. The effects of laser smoke on the lungs of rats. Am. J. Obstet. Gynecol. 156:12601265, 1987.

${ }^{7}$ Benias, P. C., and D. L. Carr-Locke. Principles of electrosurgery. Ercp 86-92:e1, 2019. https://doi.org/10.1016/b 978-0-323-48109-0.00011-0.

${ }^{8}$ Bonczyk, P. A., and J. J. Sangiovanni. Optical and probe measurements of soot in a burning fuel droplet stream. Combust. Sci. Technol. 36:135-147, 1984.

${ }^{9}$ Brüske-Hohlfeld, I., G. Preissler, K.-W. Jauch, M. Pitz, D. Nowak, A. Peters, and H.-E. Wichmann. Surgical smoke and ultrafine particles. J. Occup. Med. Toxicol. 3:31, 2008.

${ }^{10}$ Cascella, M., M. Rajnik, C. Arturo, D. S. C., and D. N. Raffaela. (2020) Features, Evaluation and Treatment Coronavirus (COVID-19). StatPearls Publishing, 2020. h ttps://www.ncbi.nlm.nih.gov/books/NBK554776/?report = classic.

${ }^{11}$ Cavina, E., O. Goletti, N. Molea, P. Buccianti, M. Chiarugi, G. Boni, E. Lazzeri, and R. Bianchi. Trocar site tumor recurrences. May pneumoperitoneum be responsible? Surg. Endosc. 12:1294-1296, 1998.

${ }^{12}$ ConMed. (2015) Operator's Manual-System 5000 Electrosurgical Unit (60-8005-SYS). 2015. http://eifu.conmed.c $\mathrm{om} /$.

${ }^{13}$ DesCôteaux, J.-G., P. Picard, É. C. Poulin, and M. Baril. Preliminary study of electrocautery smoke particles produced in vitro and during laparoscopic procedures. Surg. Endosc. 10:152-158, 1996.

${ }^{14}$ Dobrogowski, M., W. Wesołowski, M. Kucharska, A. Sapota, and L. S. Pomorski. Chemical composition of surgical smoke formed in the abdominal cavity during laparoscopic cholecystectomy-assessment of the risk to the patient. Int. J. Occup. Med. Environ. Health 27:314-325, 2014.

${ }^{15}$ Dolan, E. B., M. G. Haugh, D. Tallon, C. Casey, and L. M. McNamara. Heat-shock-induced cellular responses to temperature elevations occurring during orthopaedic cutting. J. R. Soc. Interface 9:3503-3513, 2012.

${ }^{16}$ Dolan, E. B., M. G. Haugh, M. C. Voisin, D. Tallon, and L. M. McNamara. Thermally induced osteocyte damage initiates a remodelling signaling cascade. PLOS ONE 10:117, 2015.

${ }^{17}$ Dolan, E. B., T. J. Vaughan, G. L. Niebur, C. Casey, D. Tallon, and L. M. McNamara. How bone tissue and cells experience elevated temperatures during orthopaedic cutting: an experimental and computational investigation. $J$. Biomech. Eng. 136:021019, 2014.

${ }^{18}$ Eder, C., A. Chavanne, J. Meissner, W. Bretschneider, A. Tuschel, P. Becker, and M. Ogon. Autografts for spinal fusion: osteogenic potential of laminectomy bone chips and bone shavings collected via high speed drill. Eur. Spine J. 20:1791-1795, 2011. 
${ }^{19}$ Edwards, B. E., and R. E. Reiman. Results of a survey on current surgical smoke control practices. AORN J. 87:739749, 2008.

${ }^{20}$ Edwards, B. E., and R. E. Reiman. Comparison of current and past surgical smoke control practices. AORN J. 95:337-350, 2012.

${ }^{21}$ Elmashae, Y., R. H. Koehler, M. Yermakov, T. Reponen, and S. A. Grinshpun. Surgical smoke simulation study: physical characterization and respiratory protection. Aerosol Sci. Technol. 52:38-45, 2018.

${ }^{22}$ Farrugia, M., S. Y. Hussain, and D. Perrett. Particulate matter generated during monopolar and bipolar hysteroscopic human uterine tissue vaporization. J. Minim. Invasive Gynecol. 16:458-464, 2009.

${ }^{23}$ Fitzgerald, J. E. F., M. Malik, and I. Ahmed. A singleblind controlled study of electrocautery and ultrasonic scalpel smoke plumes in laparoscopic surgery. Surg. Endosc. Other Interv. Tech. 26:337-342, 2012.

${ }^{24}$ Fletcher, J. N., D. Mew, and J.-G. DesCôteaux. Dissemination of melanoma cells within electrocautery plume. Am. J. Surg. 178:57-59, 1999.

${ }^{25}$ Gao, S., R. H. Koehler, M. Yermakov, and S. A. Grinshpun. Performance of facepiece respirators and surgical masks against surgical smoke: simulated workplace protection factor study. Ann. Occup. Hyg. 60:608-618, 2016.

${ }^{26}$ Garden, J. M. Papillomavirus in the vapor of carbon dioxide laser-treated verrucae. JAMA J. Am. Med. Assoc. 259:1199, 1988.

${ }^{27}$ Garden, J. M., M. K. O'Banion, A. D. Bakus, and C. Olson. Viral disease transmitted by laser-generated plume (aerosol). Arch. Dermatol. 138:1303-1307, 2002.

${ }^{28}$ Garden, J. M., M. K. O’Banion, L. S. Shelnitz, K. S. Pinski, A. D. Bakus, M. E. Reichmann, and J. P. Sundberg. Papillomavirus in the vapor of carbon dioxide laser-treated verrucae. JAMA 259:1199-1202, 1988.

${ }^{29}$ Gatti, J. E., C. J. Bryant, R. B. Noone, and J. B. Murphy. The mutagenicity of electrocautery smoke. Plast. Reconstr. Surg. 89:781-784, 1992; (discussion 785-6).

${ }^{30}$ Hallmo, P., and O. Naess. Laryngeal papillomatosis with human papillomavirus DNA contracted by a laser surgeon. Eur. Arch. OtorhinoLaryngol 248:425-427, 1991.

${ }^{31}$ Hensman, C., D. Baty, R. G. Willis, and A. Cuschieri. Chemical composition of smoke produced by high-frequency electrosurgery in a closed gaseous environment. Surg. Endosc. 12:1017-1019, 1998.

${ }^{32}$ In, S. M., D.-Y. Park, I. K. Sohn, C.-H. Kim, H. L. Lim, S.-A. Hong, D. Y. Jung, S.-Y. Jeong, J. H. Han, and H. J. Kim. Experimental study of the potential hazards of surgical smoke from powered instruments. $B r$. J. Surg. 102:1581-1586, 2015.

${ }^{33}$ Infection prevention and control during health care for probable or confirmed cases of novel coronavirus (nCoV) infection. World Health Organization, 2013. https://www. who.int/csr/disease/coronavirus infections/IPCnCoVguida nce_06May13.pdf.

${ }^{34}$ Johnson, G. K., and W. S. Robinson. Human immunodeficiency virus-1 (HIV-1) in the vapors of surgical power instruments. J. Med. Virol. 33:47-50, 1991.

${ }^{35}$ Karjalainen, M., A. Kontunen, S. Saari, T. Rönkkö, J. Lekkala, A. Roine, and N. Oksala. The characterization of surgical smoke from various tissues and its implications for occupational safety. PLoS ONE 13:e0195274, 2018.

${ }^{36}$ Kasten, F. Falling speed of aerosol particles. J. Appl. Meteorol. 7:944-947, 1968
${ }^{37}$ Katz, J. The Electrostatic Precipitator: Application and Concepts. Handb. Powder Sci. Technol. 753-770, 1997. https://doi.org/10.1007/978-1-4615-6373-0_16.

${ }^{38}$ Khaled, U., and A. Z. Eldein. Experimental study of V-I characteristics of wire-plate electrostatic precipitators under clean air conditions. J. Electrostat. 71:228-234, 2013.

${ }^{39}$ Krones, C. J., J. Conze, F. Hoelzl, M. Stumpf, U. Klinge, M. Möller, W. Dott, V. Schumpelick, and J. Hollender. Chemical composition of surgical smoke produced by electrocautery, harmonic scalpel and argon beaming-a short study. Eur. Surg. Acta Chir. Austriaca 39:118-121, 2007.

${ }^{40}$ Kulkarni, P., P. A. Baron, and K. Willeke. Aerosol measurement: principles, techniques, and applications. Hoboken, NJ: Wiley, 2011.

${ }^{41}$ Kuttenberger, J., E. Polska, and B. M. Schaefer. A novel three-dimensional bone chip organ culture. Clin. Oral Invest. 17:1547-1555, 2013.

${ }^{42}$ Lee, S. J., and K. H. Park. Ultrasonic energy in endoscopic surgery. Yonsei Med. J. 40:545, 1999.

${ }^{43}$ Lee, T., J.-C. Soo, R. F. LeBouf, D. Burns, D. SchweglerBerry, M. Kashon, J. Bowers, and M. Harper. Surgical smoke control with local exhaust ventilation: experimental study. J. Occup. Environ. Hyg. 15:341-350, 2018.

${ }^{44}$ Loh, S. A., G. A. Carlson, E. I. Chang, E. Huang, D. Palanker, and G. C. Gurtner. Comparative healing of surgical incisions created by the peak plasmablade, conventional electrosurgery, and a scalpel. Plast. Reconstr. Surg. 124:1849-1859, 2009.

${ }^{45}$ Massarweh, N. N., N. Cosgriff, and D. P. Slakey. Electrosurgery: history, principles, and current and future uses. J. Am. Coll. Surg. 202:520-530, 2006.

${ }^{46}$ McQuail, P. M., B. S. McCartney, J. F. Baker, and P. Kenny. Diathermy awareness among surgeons - an analysis in Ireland. Ann. Med. Surg. 12:54-59, 2016.

${ }^{47}$ Medical Face Masks-Requirements and Test Methods Standard (BS EN 14683:2019).

${ }^{48}$ Mick, P. T., and R. Murphy. Aerosol-generating otolaryngology procedures and the need for enhanced PPE during the COVID-19 pandemic: a literature review. $J$. Otolaryngol. Head Neck Surg. 49:1-10, 2020.

${ }^{49}$ Nduka, C. C., N. Poland, M. Kennedy, J. Dye, and A. Darzi. Does the ultrasonically activated scalpel release viable airborne cancer cells? Surg. Endosc. 12:1031-1034, 1998.

${ }^{50}$ Nezhat, C., W. K. Winer, F. Nezhat, C. Nezhat, D. Forrest, and W. G. Reeves. Smoke from laser surgery: Is there a health hazard? Lasers Surg. Med. 7:376-382, 1987.

${ }^{51}$ Nikas, K. S. P., A. A. Varonos, and G. C. Bergeles. Numerical simulation of the flow and the collection mechanisms inside a laboratory scale electrostatic precipitator. J. Electrostat. 63:423-443, 2005.

${ }^{52}$ Redmayne, A. C., D. Wake, R. C. Brown, and B. Crook. Measurement of the degree of protection afforded by respiratory protective equipment against microbiological aerosols. Ann. Occup. Hyg. 41:636-640, 1997.

${ }^{53}$ Romano, F., J. Gustén, S. De Antonellis, and C. M. Joppolo. Electrosurgical smoke: ultrafine particle measurements and work environment quality in different operating theatres. Int. J. Environ. Res. Public Health 2017. https://d oi.org/10.3390/ijerph14020137.

${ }^{54}$ Roth, A. A., P. C. Tang, M. J. Ye, K. S. Mohammad, and R. F. Nelson. Improved autologous cortical bone harvest and viability with 2Flute otologic burs. Laryngoscope 128:E40-E46, 2018. 
${ }^{55}$ Schulz, H., V. Harder, A. Ibald-Mulli, A. Khandoga, W. Koenig, F. Krombach, R. Radykewicz, A. Stampfl, B. Thorand, and A. Peters. Cardiovascular effects of fine and ultrafine particles. J. Aerosol Med. 18:1-22, 2005.

${ }^{56}$ Seipp, H.-M., T. Steffens, J. Weigold, A. Lahmer, A. Maier-Hasselmann, T. Herzog, and J. Herzog-Niescery. Efficiencies and noise levels of portable surgical smoke evacuation systems. J. Occup. Environ. Hyg. 0:1-20, 2018.

${ }^{57}$ Sisler, J. D., J. Shaffer, J.-C. Soo, R. F. LeBouf, M. Harper, Y. Qian, and T. Lee. In vitro toxicological evaluation of surgical smoke from human tissue. J. Occup. Med. Toxicol. 13:12, 2018.

${ }^{58}$ Song, C., B. Tang, P. A. Campbell, and A. Cuschieri. Thermal spread and heat absorbance differences between open and laparoscopic surgeries during energized dissections by electrosurgical instruments. Surg. Endosc. 23:2480-2487, 2009.

${ }^{59}$ Steege, A. L., J. M. Boiano, and M. H. Sweeney. Secondhand smoke in the operating room? Precautionary practices lacking for surgical smoke. Am. J. Ind. Med. 59:1020-1031, 2016.

${ }^{60}$ Sutton, P. A., S. Awad, A. C. Perkins, and D. N. Lobo. Comparison of lateral thermal spread using monopolar and bipolar diathermy, the Harmonic Scalpel ${ }^{\mathrm{TM}}$ and the Ligasure $^{\text {TM }}$. Br. J. Surg. 97:428-433, 2010.

${ }^{61}$ The Cell: A Molecular Approach. 2nd edition. No Title. Sunderland (MA): Sinauer Associates, 2000. https://www. ncbi.nlm.nih.gov/books/NBK9839/.
${ }^{62}$ Tomita, Y., S. Mihashi, K. Nagata, S. Ueda, M. Fujiki, M. Hirano, and T. Hirohata. Mutagenicity of smoke condensates induced by $\mathrm{CO}_{2}$-laser irradiation and electrocauterization. Mutat. Res. Toxicol. 89:145-149, 1981.

${ }^{63}$ Tseng, L. N., F. J. Berends, P. Wittich, N. D. Bouvy, R. L. Marquet, G. Kazemier, and H. J. Bonjer. Port-site metastases. Impact of local tissue trauma and gas leakage. Surg. Endosc. 12:1377-1380, 1998.

${ }^{64}$ Ulmer, B. C. The hazards of surgical smoke. AORN J. 87:737-738, 2008.

${ }^{65}$ Weld, K. J., S. Dryer, C. D. Ames, K. Cho, C. Hogan, M. Lee, P. Biswas, and J. Landman. Analysis of surgical smoke produced by various energy-based instruments and effect on laparoscopic visibility. J. Endourol. 21:347-351, 2007.

${ }^{66}$ Workman, A. D., D. B. Welling, B. S. Carter, W. T. Curry, E. H. Holbrook, S. T. Gray, G. A. Scangas, and B. S. Bleier. Endonasal instrumentation and aerosolization risk in the era of COVID-19: simulation, literature review, and proposed mitigation strategies. Int. Forum Allergy Rhinol. 2020. https://doi.org/10.1002/alr.22577.

${ }^{67}$ Zhao, L., and K. Adamiak. Numerical simulation of the electrohydrodynamic flow in a single wire-plate electrostatic precipitator. IEEE Trans. Ind. Appl. 44:683-691, 2008.

Publisher's Note Springer Nature remains neutral with regard to jurisdictional claims in published maps and institutional affiliations. 